\title{
Sensory Consciousness is Experienced through Amplification of Sensory Stimuli via Lateral Inhibition
}

\author{
Ravinder Jerath ${ }^{*}$, Shannon M. Cearley ${ }^{1}$, Ruchir Paladiya1, Vernon A. Barnes ${ }^{2}$ \\ ${ }^{1}$ Augusta Women's Center, Augusta, GA, USA \\ ${ }^{2}$ Georgia Prevention Institute, Augusta University, Augusta, GA, USA \\ Email: *rj605r@aol.com
}

How to cite this paper: Jerath, R., Cearley, S.M., Paladiya, R. and Barnes, V.A. (2017) Sensory Consciousness is Experienced through Amplification of Sensory Stimuli via Lateral Inhibition. World Journal of Neuroscience, 7, 244-256.

https://doi.org/10.4236/wjns.2017.73020

Received: April 27, 2017

Accepted: June 17, 2017

Published: June 20, 2017

Copyright $\odot 2017$ by authors and Scientific Research Publishing Inc. This work is licensed under the Creative Commons Attribution International License (CC BY 4.0).

http://creativecommons.org/licenses/by/4.0/

\begin{abstract}
At present, researchers are unclear about which activity within the brain is responsible for the emergence of consciousness-the subconscious or unconscious. Current literature suggests that consciousness is isolated in the brain; however, we suggest consciousness emerges from both-subconscious and unconscious activity, in addition to sensory consciousness. This article contends that sensory consciousness arises from neurophysiological brain activity, intrapersonal space, sensory information, and parallel processing of the external and internal environment through vision, olfaction, the integumentary system, gustation, and audition. Traditionally, lateral inhibition is defined as the ability for an excited neuron to laterally inhibit its neighbors, and is an integral part of neurophysiology in all senses. In this article, we are connecting the science behind the well-established physiological observations of gamma wave activity in the interneurons of peripheral receptors with what is currently unknown regarding the functional significance of seemingly unrelated gamma activity in the cortico-thalamic gamma oscillations. We suggest that this allows for instantaneous integration of the brain with sensory receptors. This article uses existing literature on lateral inhibition to investigate its role in sensory organs and various areas of the body. We explain how sensory consciousness is only one component of unified consciousness. We propose that lateral inhibition also plays a vital role in consciousness theory, and understanding this can help illustrate the dynamic interactions between the central and peripheral nervous systems within the body.
\end{abstract}

\section{Keywords}

Sensory Consciousness, Lateral Inhibition, Sensory Perception, Sensory Stimuli Amplification, 3D Default Space, Unified Consciousness 


\section{Introduction}

A unified 3D default space consciousness model was previously proposed describing the intrapersonal space as a virtual, dynamic space that functions as an internal template that doubles for the external space, and is created by the trillions of cells of the body that are integrated in the brain and sensory organs via afferent and efferent networks via corticothalamic feedback loops [1]. The current article expands upon this unified 3D default consciousness model, and proposes that lateral inhibition could play an integral part of the unified consciousness experience.

The entire circuit initiated by the sensory receptors, afferent neurons, ascending sensory tracts in the spinal cord, thalamus, cortico-thalamic feed forward and feedback loops, and efferent neurons in the spinal cord are sent back to the sensory receptors and all of these networks are all involved with neurocircuitry of lateral inhibition [2]. The sensory receptors are actively in an "alert" state as indicated by baseline gamma activity on electroencephalogram recordings and are generated by the spinal-thalamo-cortical activity. This increases the intensity of any external stimulus to a higher level of electrochemical-neural coding that is instantaneously perceived, which allows the body and brain to work together as one unified space [1] and not as two separate entities.

We contend that unified consciousness should include an understanding of sensory consciousness as the stimulation of the senses through lateral inhibition, which we suggest is what allows one to consciously comprehend what the stimulus represents. For example, it is well-documented that lateral inhibition plays a significant role in visual perception [3] [4] [5], audition [6], gustation [7], olfaction [8] [9] [10], integumentary and motor response [11] [12] [13], and other areas throughout the body (i.e. the intestines) [14]. These articles explain the characteristic physiological responses that are recorded, and in the olfactory senses, the data reflects the presence of lateral inhibition upon stimulation [8] [9] [10]. We suggest it is possible that other organs similarly exhibit responses that are recorded as predictable and physiological responses. In this article, we are including all the sensory organ responses together to show the functional importance for the first time. The purpose of this paper is to expand upon our previous model of unified consciousness [1] to explain how lateral inhibition allows consciousness to emerge. A schematic diagram of how lateral inhibition plays a part in the central and peripheral nervous systems has been previously published [2].

All sensory information that enters into the brain must first be converted to electrical, neural, and chemical signals, which is known as transduction [15] [16] [17]. Through the process of transduction, electrical signals are able to enter the brain [18] [19]. In sensory perception, the sensory organ receives the initial external stimuli which leads to depolarization followed by hyperpolarization [20] [21] [22] [23] [24], and is mediated by inhibitory interneurons [25] [26] [27]. Traditionally, lateral inhibition is defined as an excited neuron's capability to inhibit its laterally neighboring neurons [28]. We suggest that lateral inhibition 
could play an additional role, in that it could be responsible for amplification of sensory stimuli via hyperpolarization. The supporting evidence provides indirect evidence that our theory is plausible.

\section{Lateral Inhibition and Sensory Perception}

There is no singular definition of consciousness that is agreed upon as a whole, because consciousness is eminently complex and remarkably organized-a process that involves the mind and a person's perception of the world. In neurobiology, observations about sensory perception are not fully understood. We suggest that sensory consciousness enables a person to experience a part of consciousness through the senses. To support this theory, we review literature that provides empirical evidence of lateral inhibition in the sensory organs, and concentrate solely on sensory consciousness because consciousness is unquestionably heterogeneous. Sensory consciousness is only one important aspect of the whole conscious experience, in that the senses work in parallel-not singularly-to give us a unified experience of consciousness.

It is known that neurons use electrical currents to communicate with each other at sensory end organs, along axons, and at synapses [11]. They are electrically polarized due to their semi-permeable membrane, use changes in membrane potential to communicate through graded potential changes (used in vision) and action potentials (used to communicate over long distances) [29], and their electrical signaling is modulated by ion concentrations [11] [29]. Extant knowledge suggests that depolarized action potentials send signals, but we contend that it is possible that hyperpolarized neural signals transmit sensory neural activity. Although lateral inhibition is considered to be "an important neural mechanism in sensory organs" [30], and has been observed physiologically in the body and in all sensory organs [10] [13] [14] [31], researchers have yet to determine the specific role it plays in each of the sensory organs.

We suggest that the interactions between the brain and body work in unison to condense the external world into an internalized awareness and perception of it. For example, sensory organs make it possible for external sensory information to be magnified, amplified, and intensified (lateral inhibition) in order for the brain to make sense of the signals received, and thus allow a person to make sense of the information [32]. Therefore, we propose that lateral inhibition is critical for a sensory consciousness experience. If this model of sensory consciousness is validated, it could potentially provide guidance to the direction of the study of how consciousness emerges, and help to unlock the mystery and complexity of what consciousness is. In order to do this, researchers must first connect sensory systems (visual, auditory, integumentary, olfaction, and gustatory) as significant processes that allow the brain to fully understand the external world before consciousness can occur. Below, we describe these processes in detail and discuss how they and lateral inhibition work together to create a unified conscious experience. 


\section{Visual Processing and Lateral Inhibition}

Before vision can occur, light must be converted into chemical and electrical signals that the brain can process/understand-a phenomenon known as phototransduction [11] [29] [33] [34]. Phototransduction takes places via biochemical cycles interlinking with enormous amplification factors which transforms light waves into neuronal activity and photochemical adaptation support acclimation to the intensity of light (which is greater than 10 logarithmic units) [35]. Amplification occurs in two steps: 1) rhodopsin activates transducin, and 2) rhodopsin and phosphodiesterase $\left(\sim 10^{5}-10^{6}\right)$; processes that make it possible for rods sensitive enough to be able to detect single photons [36]. Center-surround antagonism of the receptive field is responsible for intensity amplification and color contrast [35], suggesting that lateral inhibition is not only responsible for color contrast, but it is also responsible for the amplification of light intensity.

When the initial image falls on the retina, it undergoes amplification 100,000 times through chemical and electrical transduction during lateral inhibition [33]. Direct electric conduction from one neuron to another (especially those connected laterally) begins at photoreceptor synapses without the need for a neurotransmitter [37]. It has also been suggested that proton concentration carries feedback signal to cones, and is regulated by horizontal cells [38]. We suggest that there is an instantaneous integration of corticothalamic information with the sensory organs, which thereby allows a person to experience the external world at the location where stimuli is perceived [1], which we refer to as parallel processing. This parallel processing is important, in that it allows a person to respond to positive or threatening circumstances accordingly. For complete experiences, one needs a continuous, holistic, and unified experience of the external world that is made possible through fast and slow oscillations-as opposed to a segmented experience. This allows a person to be electrically integrated and complex cellular being. Without lateral inhibition magnifying the weak sensory stimuli or inhibiting excited neighboring neurons, it would not be possible to experience the external world in a way that allows immediate interactions. A viable extent of magnification through lateral inhibition is observed at various sensory organs as described in the next sections, that explain that lateral inhibition is the mechanism that generates sensory experiences similar to that of vision.

\section{Lateral Inhibition in Audition}

Translation and amplification of weak signals transpires through the brain's ability to balance between excitation and inhibition and is essential for the processing of sound [30]. Not unlike vision, hearing takes place within the brain (as well as the ears), and the brain must be able to translate and amplify weak signals in order for hearing to occur. Lateral inhibition is likely associated with the same magnification process in hearing as is observed in vision, functioning similarly: the spectral edge of sound stimuli is enhanced in topographical frequency maps, resulting in the improvement of perception of sound [25] [39] 
[40].

Previous studies acknowledge that lateral inhibition does, in fact, take place in the auditory system [39] [41] [42], and is evidenced by: 1) occurrence of lateral inhibition in the inferior colliculus [43]; and 2) auditory information being relayed to the medial geniculate body in the thalamus [44]. The primary auditory cortex contains specialized neurons that detect frequency and intensity of sound. Lateral inhibition in audition also: 1) suppresses neighboring responses from stimuli; 2) "broadens tuning curves" [40]; 3) reduces random cortical operation instead of increasing noise [42]; or 4) becomes stronger with the intensity of sound [45].

Auditory evoked potentials are dependent upon the vestibular system [46]. Inner hair cells detect and transmit auditory information, converting "graded depolarization into trains of action potentials in auditory nerve fibers", while outer hair cells are responsible for inner ear sensitivity and fine tuning [47]. Sound and head movements are perceived through these sensory hair cells in the inner ear, initiated by mechanoelectrical transducer channels located on the tip of most stereocilia in the ears [16]. The inner and outer hair cells of the ears: 1) facilitate transduction of sound waves; 2) are controlled by "efferent inhibitory innervations"; and 3) are responsible for correlating cell length with membrane potential changes [47].

After sound, balance, proprioception, and tactile sensations are converted into electrical signals (mechanoelectrical transduction), they travel from their respective organs (eyes, ears, and skin) to the brain that processes the information in $0.1 \mathrm{~s}$ [15] [16] [17] [48] [49] [50]. This conversion of signals and their processing offers evidence that, although the time lag is in milliseconds, there is a brief delay between received sensory stimuli and conscious awareness [15] [16] [17] [48] [49] [50] [51].

\section{Lateral Inhibition and the Integumentary System}

Similar to vision and audition, tactile sensation is improved through lateral inhibition in that neighboring inhibitory interneurons modulate sensations proportionately to the information they receive [11] and are relayed to the thalamus [29]. Previous research about the integumentary system provides evidence that: 1) fingertips carry information about object curvature, force, and texture; 2) tactile afferents transmit information about object surface curvature and force direction; and 3) force direction is transmitted by afferents ending on the sides and tips of the fingers [52]. Cutaneous mechanoreceptors provide the ability to process external stimuli by converting information about touch, pressure, vibration, and skin stretch into neural signals [17], while skin oscillations carry information about external stimuli and objects (i.e. slip detection, surface properties, and texture), including pain sensation to the thalamic nuclei pathways in the brain [53] [54] [55] [56]. This evidence supports the unified 3D default space consciousness model in that all sensory information received by the brain must first be integrated by the thalamus and processed by corticothalamic feedback 
loops prior to conscious awareness [1]. The new theory being proposed here suggests that lateral inhibition also takes place in the integumentary system via cutaneous mechanoreceptors, allowing a stimulus to be magnified on the skin, thereby facilitating a more detailed internal visualization of the external environment to contribute to a unified conscious experience.

\section{Lateral Inhibition in Olfaction}

Lateral inhibition in olfaction has been described in previous studies [8] [9] [57] [58] [59] [60]. Similar to amplification of tactile sensations of the integumentary system, smell is enhanced by lateral inhibition. In the cortices that correspond to vision, audition, and mechanoreception, a stimulus can synaptically excite or inhibit any or all stimuli through "co-tuning"; however, in rats, the pyramidal cells in the neocortex prevent "co-tuning" through balance and regulation of "input and spike timing in the piriform cortex" [61]. In experiments using mice, newer findings indicate that amplification in smell occurs as calcium enters cyclic-nucleotide gated ion channels and reacts with chloride channels resulting in membrane depolarization, giving the mice the ability to smell when ion concentrations are limited [62]. In humans, the ability to adapt to an odorant is possible through physiological processes that include: 1) protein kinase phosphorylation of a receptor that can inactivate or desensitize an odorant receptor following odorant receptor and ligand interaction, and 2) odorant sensitivity adjusted by the cyclic nucleotide gated ion channels to cAMP - which is similar to how the visual system adapts to light intensity matched by environmental light intensity [63]. Within a glomerulus (and with adjacent glomeruli), periglomerular interneurons create inhibitory connections with dendrites of mitral cells [63]. Basal dendrites of mitral cells cause excitation in granule cell interneurons [63]. Granule cell interneurons provide negative feedback circuits, resulting in mitral cell and neighboring cell inhibition [63]. This suggests that odorants are intensified through excitation and lateral inhibition of the mitral cells and their neighbors.

Humans have approximately 50 million receptor cells, but have only about 350 functional genes for olfactory receptors [64]. In olfaction, excitation currents have been shown to precede inhibition currents by $\sim 10 \mathrm{~ms}$ [61]. When an odorant is inhaled for $\sim 400 \mathrm{~ms}$, the olfactory bulb remains stimulated for $1600 \mathrm{~ms}$ [65]. Furthermore, in rodents, oscillations between $15-30 \mathrm{~Hz}$ can result from exposure to an odorant, and spike timing is prevented by the $\sim 10 \mathrm{~ms}$ temporal window created from excitation preceding inhibition [66]. Afferent input "provides a mechanism to amplify sensory information" [67], which we theorize is lateral inhibition. During $0.5 \mathrm{~ms}$ at 2 milliamps of electrical stimulation of the olfactory mucosa, there is a negative peak at $19.4 \mathrm{~ms}$ [68]. Even in infants, post-presentation of an odor elicits a visible peak in negative evoked potentials (N1) at $328 \mathrm{~ms}$ followed by a positive electrical potential (P2) peak at $505 \mathrm{~ms}$ [69].

Although the olfactory system bypasses the thalamus, the olfactory sensory information is received and processed by the olfactory bulb, and relays sensory 
information from olfaction to the cortex, which functions similarly to the thalamus [70]. Therefore, we surmise that the sense of smell does play a part in the unified conscious experience through integration of sensory information through corticothalamic feedback loops, and is critical in interacting with the environment. Not only is olfaction a part of evolutionary history, to allow an organism to "identify food, potential mating partners, dangers, and enemies" and remember the experience-but now is important in behavior modulation, social relationships, stimulating appetite, and influencing taste [64]. The new theory proposes that information from sensory stimuli is inserted into the $3 \mathrm{D}$ default space (and remembered) to provide a person with a unified conscious experience of the external environment.

\section{Lateral Inhibition in Gustation}

The sense of taste is a complex process that involves multisensory integration, chemical processes, and physical properties of food and beverages [71]. During the process of eating, "mastication activates the gustatory, somatosensory, and olfactory systems" [72], and in humans, taste is made possible by the gustatory epithelia [73]. Gustatory experience uses neurotransmitters and neuropeptides (cholecystokinin, neuropeptide Y, vasoactive intestinal peptide, glucagon-like peptide-1), that have been shown to work in parallel to modulate excitatory bitter-sensitive cells while inhibiting sweet-sensitive cells [7], suggesting lateral inhibition must take place for flavor specificity to occur.

In humans, the end organs of gustation are the taste buds [74], and temperature, odor, and vision are determining factors in whether a food (or beverage) is desirable [72] [75]. Taste bud interactions with combinations of stimuli (i.e. salt and toxins) exhibit inhibition, and can interact to suppress or enhance each other [73]. This indicates that lateral inhibition is significant in taste perception. We suggest that this is indicative that taste is enhanced through lateral inhibition, which has been demonstrated in mice during sour taste transduction through intracellular acidification [62]. Although there is not much research regarding lateral inhibition in gustatory response, it has been shown that axonal branches are capable of inhibiting the same or lateral taste units, because neurons can activate inhibitory neighboring interneurons, producing action potentials [76].

\section{Lateral Inhibition Allows Specificity}

We suggest that lateral inhibition allows for specificity in sensation through interneuronal augmentation and amplification of electrical signals from the brain to the peripheral senses. Without this augmentation and amplification of weak signals, in addition to the inhibition of neighboring excited neurons, conscious perception of the external world would not be possible.

The human body is purposeful in the conservation of energy and is efficient at doing so; suggesting that, metabolic processes do not occur without serving a higher function. This is supported by evidence observed in patients in comatose states (induced by damage to the brain) that prevent corticothalamic activity; the 
electroretinography signals are received from lateral inhibition, but are unable to be processed [77] [78]. We propose that lateral inhibition does not exist just to simply exist-we are proposing that it serves a purpose, that is, to provide us with a more complete and unified consciousness through sensory consciousness. Although lateral inhibition does play a part in sensory perception, the mechanism that produces lateral inhibition remains unknown [3] [79].

\section{Conclusions}

Evidence provided supports our theory that sensory consciousness is indeed a part of the unified consciousness experience, and the experience of the external world is only possible through the senses. Therefore, lateral inhibition could be fundamental in the role of sensory consciousness. It is the sensitivity to the stimuli that allows a person to experience the world, and to respond to external sensory stimuli accordingly. Each sensory organ must receive and magnify or inhibit sensory signals, and the brain must convert them into electric or chemical signals before the sensations can rise to consciousness. We propose that lateral inhibition may have a fundamental role to play in the emergence of sensory consciousness. Unified consciousness is a heterogeneous process; therefore, the experience of consciousness as a whole is a very complex combination of individual processes that work together to give us the experience of unified consciousness.

The contention is that lateral inhibition not only allows excited neurons to inhibit neighboring neurons, but is also responsible for amplification of sensory stimuli. The new theory proposed in this paper suggests that external sensory stimuli are converted into electrical signals, processed through the corticothalamic feedback loops, and integrated with the thalamus to recreate the external information into an internal representation, providing the mind with a unified conscious experience. This expansion to the unified 3D default space consciousness model only addresses the sensory component of consciousness. Once the functionality of lateral inhibition is confirmed, studies involving monitoring of this physiology for these components of consciousness are more likely to be conducted. Future research should include simultaneous monitoring of intraoperative sensory cortex and the corresponding skin interneuronal and neural activity. This would show an identical frequency at rest that encodes the external signal by lateral inhibition upon external stimulation confirming that lateral inhibition and consciousness work together to form a unified consciousness experience.

\section{Conflict of Interest}

All the authors declare that there were no actual or personal conflicts of interest, including financial, personal, or other relationships, people, or organizations that would influence or be perceived to influence their work while writing this manuscript. All pictures in this article are the original work of the medical artist, and all proposed theories are the original ideas of the authors. 


\section{Funding}

All the authors declare that no sponsors, funding, or financial support was granted in the writing of this manuscript.

\section{References}

[1] Jerath, R., Crawford, M.W. and Barnes, V.A. (2015) A Unified 3D Default Space Consciousness Model Combining Neurological and Physiological Processes That Underlie Conscious Experience. Frontiers in Psychology, 6, 1204. https://doi.org/10.3389/fpsyg.2015.01204

[2] Jerath, R., et al. (2016) How Lateral Inhibition and Fast Retinogeniculo-Cortical Oscillations Create Vision: A New Hypothesis. Medical Hypotheses, 96, 20-29. https://doi.org/10.1016/j.mehy.2016.09.015

[3] Kramer, R.H. and Davenport, C.M. (2015) Lateral Inhibition in the Vertebrate Retina: The Case of the Missing Neurotransmitter. PLOS Biology, 13, e1002322. https://doi.org/10.1371/journal.pbio.1002322

[4] Wang, T.M., Holzhausen, L.C. and Kramer, R.H. (2014) Imaging an Optogenetic pH Sensor Reveals That Protons Mediate Lateral Inhibition in the Retina. Nature Neuroscience, 17, 262-268. https://doi.org/10.1038/nn.3627

[5] Zhang, C., Nobles, R.D. and Mc, C.M. (2015) GlyRalpha2, Not GlyRalpha3, Modulates the Receptive Field Surround of OFF Retinal Ganglion Cells. Visual Neuroscience, 32, E026. https://doi.org/10.1017/S0952523815000280

[6] Ammer, J.J., Siveke, I. and Felmy, F. (2015) Activity-Dependent Transmission and Integration Control the Timescales of Auditory Processing at an Inhibitory Synapse. Current Biology, 25, 1562-1572. https://doi.org/10.1016/j.cub.2015.04.026

[7] Herness, S. and Zhao, F.L. (2009) The Neuropeptides CCK and NPY and the Changing View of Cell-to-Cell Communication in the Taste Bud. Physiology \& Behavior, 97, 581-591. https://doi.org/10.1016/j.physbeh.2009.02.043

[8] Margrie, T.W., Sakmann, B. and Urban, N.N. (2001) Action Potential Propagation in Mitral Cell Lateral Dendrites is Decremental and Controls Recurrent and Lateral Inhibition in the Mammalian Olfactory Bulb. Proceedings of the National Academy of Sciences, 98, 319-334. https://doi.org/10.1073/pnas.98.1.319

[9] Najac, M., et al. (2015) Intraglomerular Lateral Inhibition Promotes Spike Timing Variability in Principal Neurons of the Olfactory Bulb. The Journal of Neuros cience, 35, 4319-4331. https://doi.org/10.1523/JNEUROSCI.2181-14.2015

[10] Yu, Y., et al. (2014) Sparse Coding and Lateral Inhibition Arising from Balanced and Unbalanced Dendrodendritic Excitation and Inhibition. The Journal of Neuroscience, 34, 13701-13713. https://doi.org/10.1523/JNEUROSCI.1834-14.2014

[11] Nicholls, J., et al. (2001) From Neuron to Brain. 4th Edition, Sinauer Associates, Inc, Sunderland, Massachusetts.

[12] Sil'kis, I.G. (2006) A Possible Mechanism for the Effect of Modifiable Lateral Inhibition in the Striatum on the Selection of Conditioned Reflex Motor Responses. Neuroscience and Behavioral Physiology, 36, 631-643. https://doi.org/10.1007/s11055-006-0068-y

[13] Poston, B., et al. (2012) Cortical Silent Period Duration and Its Implications for Surround Inhibition of a Hand Muscle. European Journal of Neuroscience, 36, 2964-2971. https://doi.org/10.1111/j.1460-9568.2012.08212.x

[14] Sancho, R., Cremona, C.A. and Behrens, A. (2015) Stem Cell and Progenitor Fate in the Mammalian Intestine: Notch and Lateral Inhibition in Homeostasis and Disease. EMBO Reports, 16, 571-581. https://doi.org/10.15252/embr.201540188 
[15] Xiong, W., et al. (2012) TMHS Is an Integral Component of the Mechanotransduction Machinery of Cochlear Hair Cells. Cell, 151, 1283-1295. https://doi.org/10.1016/j.cell.2012.10.041

[16] Gerka-Stuyt, J., et al. (2013) Transient Receptor Potential Melastatin 1: a Hair Cell Transduction Channel Candidate. PLoS One, 8, e77213. https://doi.org/10.1371/journal.pone.0077213

[17] Hao, J., et al. (2015) Transduction and Encoding Sensory Information by Skin Mechanoreceptors. Pflügers Archiv European Journal of Physiology, 467, 109-119. https://doi.org/10.1007/s00424-014-1651-7

[18] Fettiplace, R. and Kim, K.X. (2014) The Physiology of Mechanoelectrical Transduction Channels in Hearing. Physiological Reviews, 94, 951-986. https://doi.org/10.1152/physrev.00038.2013

[19] Niculescu, D. and Lohmann, C. (2014) Gap Junctions in Developing Thalamic and Neocortical Neuronal Networks. Cerebral Cortex, 24, 3097-3106. https://doi.org/10.1093/cercor/bht175

[20] Seidemann, E., et al. (2002) Dynamics of Depolarization and Hyperpolarization in the Frontal Cortex and Saccade Goal. Science, 295, 862-865. https://doi.org/10.1126/science.1066641

[21] Baccus, S.A. and Meister, M. (2002) Fast and Slow Contrast Adaptation in Retinal Circuitry. Neuron, 36, 909-919. https://doi.org/10.1016/S0896-6273(02)01050-4

[22] Demb, J.B. (2002) Multiple Mechanisms for Contrast Adaptation in the Retina. Neuron, 36, 781-783. https://doi.org/10.1016/S0896-6273(02)01100-5

[23] Ojima, H. (2011) Interplay of Excitation and Inhibition Elicited by Tonal Stimulation in Pyramidal Neurons of Primary Auditory Cortex. Neuroscience and Biobehavioral Reviews, 35, 2084-2093. https://doi.org/10.1016/j.neubiorev.2010.11.009

[24] Kubota, M., Sugimoto, S. and Horikawa, J. (2008) Dynamic Spatiotemporal Inhibition in the Guinea Pig Auditory Cortex. Neuroreport, 19, 1691-1694. https://doi.org/10.1097/WNR.0b013e32831579ff

[25] Paolini, A.G., et al. (2004) Fast Inhibition Alters First Spike Timing in Auditory Brainstem Neurons. The Journal of Neurophysiology, 92, 2615-2621. https://doi.org/10.1152/jn.00327.2004

[26] Cardini, F. and Longo, M.R. (2016) Congruency of Body-Related Information Induces Somatosensory Reorganization. Neuropsychologia, 84, 213-221. https://doi.org/10.1016/j.neuropsychologia.2016.02.013

[27] Egger, V., Svoboda, K. and Mainen, Z.F. (2003) Mechanisms of Lateral Inhibition in the Olfactory Bulb: Efficiency and Modulation of Spike-Evoked Calcium Influx into Granule Cells. The Journal of Neuroscience, 23, 7551-7558.

[28] Cohen, R.A. (2011) Lateral Inhibition. In: Kreutzer, J.S., DeLuca, J. and Caplan, B., Eds., Encyclopedia of Clinical Neuropsychology, Springer, New York, 1436-1437. https://doi.org/10.1007/978-0-387-79948-3_1379

[29] Nolte, J. (1999) The Human Brain : An Introduction to Its Functional Anatomy. MO: Mosby, St. Louis.

[30] Stein, A., et al. (2013) Modulatory Effects of Spectral Energy Contrasts on Lateral Inhibition in the Human Auditory Cortex: An MEG Study. PLoS One, 8, e80899. https://doi.org/10.1371/journal.pone.0080899

[31] Iliopoulos, F., Nierhaus, T. and Villringer, A. (2014) Electrical Noise Modulates Perception of Electrical Pulses in Humans: Sensation Enhancement via Stochastic Resonance. Journal of Neurophysiology, 111, 1238-1248.

https://doi.org/10.1152/jn.00392.2013 
[32] Jerath, R., et al. (2016) Meditation Experiences, Self, and Boundaries of Consciousness. International Journal of Complementary \& Alternative Medicine, 4, 1-11.

[33] Malmivuo, J. and Plonsey, R. (1995) Bioelectromagnetism: Principles and Applications of Bioelectric and Biomagnetic Fields. Oxford University Press, Oxford. https://doi.org/10.1093/acprof:oso/9780195058239.001.0001

[34] Molday, R.S. and Moritz, O.L. (2015) Photoreceptors at a Glance. Journal of Cell Science, 128, 4039-4045. https://doi.org/10.1242/jcs.175687

[35] Eysel, U. (2007) Signal Reception and Processing by the Retina. Ophthalmologe, 104, 79-90, quiz 91. https://doi.org/10.1007/s00347-006-1460-2

[36] Fu, Y. (1995) Phototransduction in Rods and Cones. In: Kolb, H., Fernandez, E. and Nelson, R., Eds. Webvision: The Organization of the Retina and Visual System, University of Utah Health Sciences Center, Salt Lake City, UT.

[37] Warren, T.J., et al. (2016) Kinetics of Inhibitory Feedback from Horizontal Cells to Photoreceptors: Implications for an Ephaptic Mechanism. The Journal of Neuroscience, 36, 10075-10088. https://doi.org/10.1523/JNEUROSCI.1090-16.2016

[38] Vessey, J.P., et al. (2005) Proton-Mediated Feedback Inhibition of Presynaptic Calcium Channels at the Cone Photoreceptor Synapse. The Journal of Neuroscience, 25, 4108-4117. https://doi.org/10.1523/JNEUROSCI.5253-04.2005

[39] Okamoto, H., et al. (2007) Asymmetric Lateral Inhibitory Neural Activity in the Auditory System: A Magnetoencephalographic Study. BMC Neuroscience, 8, 33. https://doi.org/10.1186/1471-2202-8-33

[40] Pantev, C., Okamoto, H. and Teismann, H. (2012) Music-Induced Cortical Plasticity and Lateral Inhibition in the Human Auditory Cortex as Foundations for Tonal Tinnitus Treatment. Frontiers in Systems Neuroscience, 6, 50. https://doi.org/10.3389/fnsys.2012.00050

[41] Hancock, K.E., Davis, K.A. and Voigt, H.F. (1997) Modeling Inhibition of Type II Units in the Dorsal Cochlear Nucleus. Biological Cybernetics, 76, 419-428. https://doi.org/10.1007/s004220050355

[42] Wehr, M. and Zador, A.M. (2003) Balanced Inhibition Underlies Tuning and Sharpens Spike Timing in Auditory Cortex. Nature, 426, 442-446. https://doi.org/10.1038/nature02116

[43] Castelo-Branco, M., Neuenschwander, S. and Singer, W. (1998) Synchronization of Visual Responses between the Cortex, Lateral Geniculate Nucleus, and Retina in the Anesthetized Cat. The Journal of Neuroscience, 18, 6395-6410.

[44] Purves, D., et al. (2001) Neuroscience. 2nd Edition, Sinauer Associates, Sunderland, MA.

[45] Keine, C. and Rubsamen, R. (2015) Inhibition Shapes Acoustic Responsiveness in Spherical Bushy Cells. The Journal of Neuroscience, 35, 8579-8592. https://doi.org/10.1523/JNEUROSCI.0133-15.2015

[46] Todd, N.P. and Lee, C.S. (2015) Source Analysis of Electrophysiological Correlates of Beat Induction as Sensory-Guided Action. Frontiers in Psychology, 6, 1178. https://doi.org/10.3389/fpsyg.2015.01178

[47] Goutman, J.D., Elgoyhen, A.B. and Gomez-Casati, M.E. (2015) Cochlear Hair Cells: The Sound-Sensing Machines. FEBS Letters, 589, 3354-3361. https://doi.org/10.1016/j.febslet.2015.08.030

[48] Galambos, R., et al. (2005) The Human Retinal Functional Unit. International Journal of Psychophysiology, 57, 187-194. https://doi.org/10.1016/j.ijpsycho.2005.01.013 
[49] Del Cul, A., Baillet, S. and Dehaene, S. (2007) Brain Dynamics Underlying the Nonlinear Threshold for Access to Consciousness. PLOS Biology, 5, e260. https://doi.org/10.1371/journal.pbio.0050260

[50] Bokkon, I. (2009) Visual Perception and Imagery: A New Molecular Hypothesis. Biosystems, 96, 178-184. https://doi.org/10.1016/j.biosystems.2009.01.005

[51] Inui, K., et al. (2006) Serial and Parallel Processing in the Human Auditory Cortex: A Magnetoencephalographic Study. Cereb Cortex, 16, 18-30. https://doi.org/10.1093/cercor/bhi080

[52] Saal, H.P., Vijayakumar, S. and Johansson, R.S. (2009) Information about Complex Fingertip Parameters in Individual Human Tactile Afferent Neurons. The Journal of Neuroscience, 29, 8022-8031. https://doi.org/10.1523/JNEUROSCI.0665-09.2009

[53] Mackevicius, E.L., et al. (2012) Millisecond Precision Spike Timing Shapes Tactile Perception. The Journal of Neuroscience, 32, 15309-15317. https://doi.org/10.1523/JNEUROSCI.2161-12.2012

[54] Davis, K.D., et al. (1998) Functional MRI Study of Thalamic and Cortical Activations Evoked by Cutaneous Heat, Cold, and Tactile Stimuli. The Journal of Neuroscience, 80, 1533-1546.

[55] Coghill, R.C., et al. (1999) Pain Intensity Processing within the Human Brain: A Bilateral, Distributed Mechanism. The Journal of Neuroscience, 82, 1934-1943.

[56] Moore, J.D., et al. (2015) Vibrissa Self-Motion and Touch Are Reliably Encoded along the Same Somatosensory Pathway from Brainstem through Thalamus. PLOS Biology, 13, e1002253. https://doi.org/10.1371/journal.pbio.1002253

[57] Bartel, D.L., et al. (2015) Dendrodendritic Synapses in the Mouse Olfactory Bulb External Plexiform Layer. The Journal of Comparative Neurology, 523, 1145-1161. https://doi.org/10.1002/cne.23714

[58] Mori, K., Nagao, H. and Yoshihara, Y. (1999) The Olfactory Bulb: Coding and Processing of Odor Molecule Information. Science, 286, 711-715. https://doi.org/10.1126/science.286.5440.711

[59] Urban, N.N. (2002) Lateral Inhibition in the Olfactory Bulb and in Olfaction. Physiology \& Behavior, 77, 607-612. https://doi.org/10.1016/S0031-9384(02)00895-8

[60] Vucinic, D., Cohen, L.B. and Kosmidis, E.K. (2006) Interglomerular Center-Surround Inhibition Shapes Odorant-Evoked Input to the Mouse Olfactory Bulb in Vivo. Journal of Neurophysiology, 95, 1881-1887. https://doi.org/10.1152/jn.00918.2005

[61] Isaacson, J.S. (2010) Odor Representations in Mammalian Cortical Circuits. Current Opinion in Neurobiology, 20, 328-331. https://doi.org/10.1016/j.conb.2010.02.004

[62] Ye, W., et al. (2016) The K+ Channel KIR2.1 Functions in Tandem with Proton Influx to Mediate Sour Taste Transduction. Proceedings of the National Academy of Sciences of the United States of America, 113, E229-238. https://doi.org/10.1073/pnas.1514282112

[63] Buck, L.B. and Bargmann, C. (2000) Smell and Taste: the Chemical Senses. Principles of Neural Science, 4, 625-647.

[64] Sarafoleanu, C., et al. (2009) The Importance of the Olfactory Sense in the Human Behavior and Evolution. Journal of Medicine and Life, 2, 196-198.

[65] Kaplan, B.A. and Lansner, A. (2014) A Spiking Neural Network Model of Self-Organized Pattern Recognition in the Early Mammalian Olfactory System. Frontiers in Neural Circuits, 8, 5. https://doi.org/10.3389/fncir.2014.00005 
[66] Poo, C. and Isaacson, J.S. (2009) Odor Representations in Olfactory Cortex: "Sparse" Coding, Global Inhibition, and Oscillations. Neuron, 62, 850-861. https://doi.org/10.1016/j.neuron.2009.05.022

[67] Vaaga, C.E. and Westbrook, G.L. (2016) Parallel Processing of Afferent Olfactory Sensory Information. Journal of Physiology, 594, 6715-6732. https://doi.org/10.1113/JP272755

[68] Martin-Loeches, M., Barcelo, F. and Rubia, F.J. (1997) Sources and Topography of Supramodal Effects of Spatial Attention in ERP. Brain Topography, 10, 9-22. https://doi.org/10.1023/A:1022254822290

[69] Schriever, V.A., et al. (2014) Olfactory Event-Related Potentials in Infants. The Journal of Pediatrics, 165, 372-375.E2

[70] Kay, L.M. and Sherman, S.M. (2007) An Argument for an Olfactory Thalamus. Trends in Neurosciences, 30, 47-53. https://doi.org/10.1016/j.tins.2006.11.007

[71] Siegel, G.J., et al. (1999) Basic Neurochemistry. Lippincott-Raven, Philadelphia, PA.

[72] de Araujo, I.E. and Simon, S.A. (2009) The Gustatory Cortex and Multisensory Integration. International Journal of Obesity, 33, 34-43. https://doi.org/10.1038/ijo.2009.70

[73] Breslin, P.A. (2013) An Evolutionary Perspective on Food and Human Taste. Current Biology, 23, R409-418. https://doi.org/10.1016/j.cub.2013.04.010

[74] Kinnamon, S.C. (2012) Taste Receptor Signalling-From Tongues to Lungs. Acta Physiologica (Oxford), 204, 158-168. https://doi.org/10.1111/j.1748-1716.2011.02308.x

[75] Breza, J.M., Curtis, K.S. and Contreras, R.J. (2006) Temperature Modulates Taste Responsiveness and Stimulates Gustatory Neurons in the Rat Geniculate Ganglion. Journal of Neurophysiology, 95, 674-685. https://doi.org/10.1152/jn.00793.2005

[76] Riddle, D.R., et al. (1990) Inhibitory Interactions among Rodent Taste Axons. Brain Research, 533, 113-124. https://doi.org/10.1016/0006-8993(90)91803-O

[77] Machado, C. (1993) Multimodality Evoked Potentials and Electroretinography in a Test Battery for an Early Diagnosis of Brain Death. Journal of Neurosurgical Sciences, 37, 125-131.

[78] Machado-Curbelo, C. and Roman-Murga, J.M. (1998) Usefulness of Multimodal Evoked Potentials and the Electroretinogram in the Early Diagnosis of Brain Death. Revista De Neurologia, 27, 809-817.

[79] Hirasawa, H., Yamada, M. and Kaneko, A. (2012) Acidification of the Synaptic Cleft of Cone Photoreceptor Terminal Controls the Amount of Transmitter Release, thereby Forming the Receptive Field Surround in the Vertebrate Retina. The Journal of Physiological Sciences, 62, 359-375. https://doi.org/10.1007/s12576-012-0220-0 
Submit or recommend next manuscript to SCIRP and we will provide best service for you:

Accepting pre-submission inquiries through Email, Facebook, LinkedIn, Twitter, etc. A wide selection of journals (inclusive of 9 subjects, more than 200 journals)

Providing 24-hour high-quality service

User-friendly online submission system

Fair and swift peer-review system

Efficient typesetting and proofreading procedure

Display of the result of downloads and visits, as well as the number of cited articles Maximum dissemination of your research work

Submit your manuscript at: http://papersubmission.scirp.org/

Or contact wins@scirp.org 